\title{
Determinación de oligómeros en ácido poliláctico, PLA, biopolímero destinado al envase alimentario
}

\author{
Sara Ubeda, Marga Aznar, Cristina Nerín \\ Grupo universitario de investigación analítica (GUIA) \\ Instituto de Investigación en Ingeniería de Aragón (I3A) \\ Universidad de Zaragoza, Mariano Esquillor s/n, 50018, Zaragoza, Spain. \\ Tel. +34-976762707, subeda@gmail.com
}

\section{Resumen}

El PLA (ácido poliláctico) es uno de los biopolímeros más utilizado para contacto alimentario. En este trabajo se ha llevado a cabo la determinación de los principales oligómeros presentes en el PLA y en la migración con tres simulantes alimentarios diferentes. Los análisis se llevaron a cabo mediante UPLC-MS-QTOF.

\section{Introducción}

El PLA es un biopolímero muy utilizado como material para contacto con alimentos debido a sus buenas características parecidas a las del PET y su biodegradabilidad. Para evaluar la seguridad de este material en su uso como envase alimentario, es importante determinar las sustancias no añadidas intencionadamente (NIAS) que se pueden formar durante su procesado. $\mathrm{Al}$ estar en contacto alimento $\mathrm{y}$ envase, estas sustancias pueden migrar al alimento, suponiendo un riesgo para la salud del consumidor. Entre los NIAS, cabe destacar los oligómeros $[1,2]$, sustancias cuya migración no debe exceder $0.01 \mathrm{mg} / \mathrm{kg}$ de alimento según la regulación europea 10/2011 [3]. El principal problema de estos compuestos es que no están incluidos en ninguna base de datos y no existen patrones, por lo que es importante estudiarlos en detalle y desarrolar nuevas metodologías para su análisis que permitan su detección.

En este trabajo se ha determinado el perfil de los oligómeros presentes en el PLA llevando a cabo la disolución total del material. Además, se ha realizado la migración específica para determinar las modificaciones en el perfil de los oligómeros al estar en contacto con simulantes alimentarios.

\section{Materiales y métodos}

\section{Muestra y tratamiento de muestra}

La muestra analizada fue un film de PLA destinado a envase alimentario. La disolución total del material se realizó con diclorometano como solvente y etanol como antisolvente. Las condiciones para la migración específica fueron 10 días a $60^{\circ} \mathrm{C}$ y se utilizaron tres simulantes alimentarios (etanol $95 \%$, etanol $10 \%$ y ácido acético $3 \%$ ).

\section{Instrumentación}

Para el análisis de los oligómeros se utilizó un cromatógrafo de líquidos de ultra alta resolución acoplado a un espectrómetro de masas con cuadrupolo y tiempo de vuelo (UPLC-MS-TOF). Se trabajó en modo $\mathrm{MS}^{\mathrm{E}}$ adquiriendo un rango de masas de 50 a 1200. Para el análisis cromatográfico, se utilizó una columna apolar (C18) y como fase móvil se utilizó metanol y agua con $0.1 \%$ de ácido fórmico.

\section{Resultados y discusión}

En la tabla 1 se muestran todos los tipos de oligómeros, cíclicos y lineales, identificados en la muestra de PLA. Todos ellos están compuestos por el monómero lactida, [LA] $\left(\mathrm{C}_{3} \mathrm{H}_{4} \mathrm{O}_{2}\right)$. Las estructuras corresponden a las fórmulas $[\mathrm{LA}]_{\mathrm{n}}, \mathrm{OH}-$ $[\mathrm{LA}]_{\mathrm{n}}-\mathrm{H}$ and $\mathrm{CH}_{3}-\mathrm{O}-[\mathrm{LA}]_{\mathrm{n}}-\mathrm{CH}_{3}$, dónde $\mathrm{n}$ es el número de veces que el monómero se repite [4]. En total se han identificado 39 oligómeros diferentes tanto cíclicos, $[\mathrm{LA}]_{\mathrm{n}} \mathrm{n}=5-16$ como lineales, $\mathrm{OH}-$ $[\mathrm{LA}]_{\mathrm{n}}-\mathrm{H} \mathrm{n}=3-15$ y CH$_{3}-\mathrm{O}-[\mathrm{LA}]_{\mathrm{n}}-\mathrm{CH}_{3} \mathrm{n}=2-15$.

La figura 2 representa el sumatorio de las áreas de los oligómeros del mismo tipo en los distintos tipos de ensayo, disolución del material y en la migración con tres simulantes. Los oligómeros cíclicos $[\mathrm{LA}]_{\mathrm{n}}$ 
sólo aparecen en la disolución total del material y no están presentes en las muestras de migración. Sin embargo, los oligómeros lineales están presentes principalmente en las disoluciones de migración, muy probablemente porque en contacto con los simulantes acuosos los ciclos se hidrolizan y se abren. Los oligómeros lineales con estructura HO$[\mathrm{LA}]_{\mathrm{n}}-\mathrm{H}$ aparecen en migraciones con los dos simulantes acuosos (EtOH 10\% and HAc 3\%) mientras que los oligómeros lineales con estructura $\mathrm{CH}_{3}-\mathrm{O}-[\mathrm{LA}]_{\mathrm{n}}-\mathrm{CH}_{3}$ están presentes únicamente cuando se utilizan simulantes que contienen etanol (EtOH 95\% and EtOH 10\%).

\section{Conclusiones}

La disolución total/precipitación del PLA utilizando DCM/EtOH como solvente/antisolvente es un buen tratamiento de muestra para la identificación de los principales oligómeros presentes en el material, tratándose en su mayoría de oligómeros cíclicos. Los ensayos de migración mostraron la presencia de oligómeros lineales en todos los simulantes. El perfil de oligómeros determinados en la migración dependió del simulante utilizado por lo que dependiendo del alimento envasado en un mismo material de PLA los compuestos que migraran pueden ser diferentes.

Por otro lado, se concluye que es importante disponer de la metodología adecuada para

Tabla 1. Tipos de oligomeros identificados en la muestra de PLA.

\begin{tabular}{|c|c|c|}
\hline $\begin{array}{c}\text { Tipo de } \\
\text { oligomero }\end{array}$ & Estructura & $n$ \\
\hline Cíclico & {$[\mathrm{LA}] \mathrm{n}$} & $5-16$ \\
\hline Lineal & OH-[LA]n-H & $3-15$ \\
\hline Lineal & CH3-O-[LA]n-CH3 & $2-15$ \\
\hline
\end{tabular}

identificar y cuantificar los oligómeros presentes en los envases alimentarios ya que no se conoce su toxicidad y la legislación europea los incluye como NIAS, por lo que su límite de migración máximo debe ser inferior a $0.01 \mathrm{mg} / \mathrm{kg}$. El análisis por UPLC-MS-QTOF es una buena herramienta para su determinación.

\section{REFERENCIAS}

[1] HOPPE, M., DE VOOGT, P., FRANZ, R. Identification and quantification of oligomers as potential migrants in plastics food contact materials with a focus in polycondensates -A review. Trends in Food Science \& Technology, 2016, 50, 118130.

[2] UBEDA, S., AZNAR, M., NERIN, C. Determination of oligomers in virgin and recycled polyethylene terephthalate (PET) samples by UPLC-MS-QTOF. Analytical and Bioanalytical Chemistry, 2018, 410, 2377-2384.

[3] EC Commission regulation (EU) no 10/2011 of 14 January 2011 on plastic materials and articles intended to come into contact with food 2011, Official Journal of the European Union(L12:1 89).

[4] BADÍA, J.D., STRÖMBERG, E., RIBES-GREUS, A., KARLSOON, S. Assessing the MALDI-TOF MS sample preparation procedure to analyze the influence of thermooxidative ageing and thermo-mechanical degradation on poly (Lactide). European Polymer Journal, 2011, 47(7), 1416-1428.

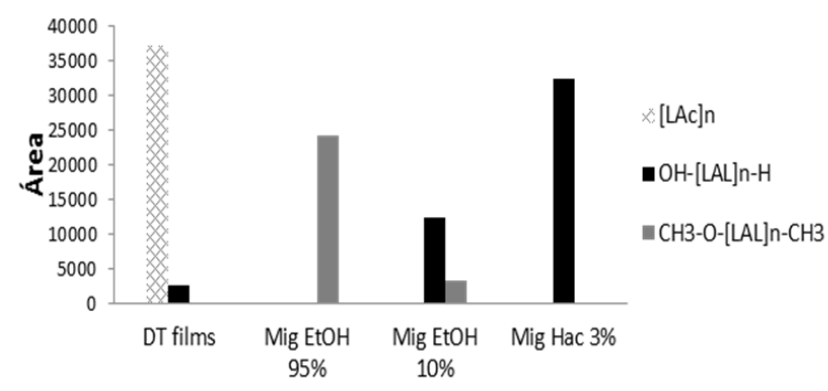

Fig. 1. Áreas totales de los tipos de oligomeros en disolución total y migración. 